\title{
MODELLING AND SIMULATION OF HUMAN DECISION-MAKING IN MANUFACTURING SYSTEMS
}

\author{
Gert Zülch \\ ifab-Institute of Human and Industrial Engineering \\ University of Karlsruhe \\ Kaiserstrasse 12, D-76131 Karlsruhe, Germany
}

\begin{abstract}
The simulation of manufacturing processes mainly focuses on the structure of machinery resources and the flow of material, but the inclusion of the personnel in the simulation model is only slowly gaining in importance. When personnel resources are modelled, merely the operative tasks are represented. However, as a result of modern manufacturing concepts, worker decisions at a workshop level are becoming more and more important. This article deals with various concepts for the modelling of human decisions in manufacturing systems, namely from human decision makers as passive resources over the modelling of decisions based on global rules to the modelling of active decision makers with individual, locally valid decisionmaking rules. Each of these various types of modelling will be elucidated using an application example.
\end{abstract}

\section{HUMAN DECISIONS IN THE MANUFACTURING AREA}

\subsection{Development of Personnel Simulators}

To a great extent in the simulation-supported planning of manufacturing systems, only the configuration of facilities for the flow of material and machines are taken into account. The influence of humans on the manufacturing operations is often neglected. In this case, one assumes that, at the time of realization of the planning results, a personnel structure of sufficient numbers and qualifications is available, and thus does not represent a bottleneck within the manufacturing processes. This simplifying assumption is, however, by no means realistic, as difficulties during the ramp-up of manufacturing systems often show.

In this context, the Association of German Engineers (Verein Deutscher Ingenieure) published a guideline (VDI 3633 , part 6,2001 ) regarding the modelling of humans in logistic, flow-of-material and production systems. This guideline summarizes the state of the art of modelling hu- mans in this application field. In the German-speaking countries, the development of personnel-oriented simulators had its origin in the 1980s, when personnel assignment at NC-controlled machines and in other automated manufacturing systems was recognized as a special problem area (Klauke 1980; Häußermann 1980; Zülch 2000).

\subsection{Modelling Humans as a Passive Resource}

The interplay between human and machinery resources is usually represented in such a manner that a work operation can only then be processed if both the allocated equipment as well as a person suitable for the processing are available. Thus, in simulated work operations, both machines and personnel are considered as passive resources. In addition, material and manufacturing aids, which also have to be available in order for the work operation to begin, may also be taken into consideration.

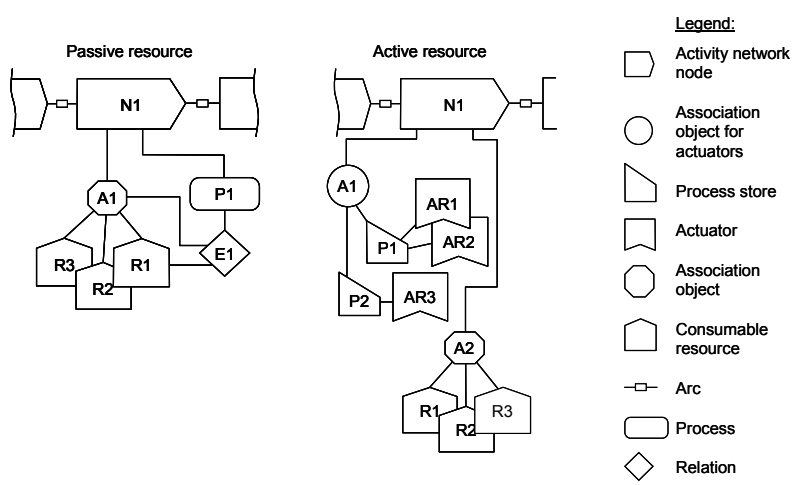

Figure 1: Modelling Active and Passive Resources Using the Simulation Procedure OSim (Zülch, Fischer, and Jonsson 2000 , pp. 374,376 )

In recent times, this modelling approach has been supplemented so that the modelled personnel may also be considered as an active resource (Fig. 1). In simulation an active resource is, in contrast to a passive one, able to execute work operations based on actual information and 
goals. This approach is reminiscent of agent-based modelling, which, in its original formulation, was conceived as a relationship between suppliers and demanders. This approach, however, did not prove to be suited to representing work operations in the manufacturing area in a realistic manner. Here, approaches based on global or local decision-making rules tend to be much more promising.

\subsection{Classification of Human Decisions in Manufacturing Processes}

In order to model human decisions in manufacturing processes, we will hereafter differentiate between the following classes:

1. Decision operation with a passive resource.

The decision is modelled as an operation with a temporal requirement and for whose execution at least one person as a passive resource is required. This does not include conclusions as to how the decision is made, rather only that, after a certain period of time, the decision operation will have been completed.

2. Decision operation based on a global rule.

In this scenario, a decision is made based on a generally valid rule in the modelled system as to which activity from amongst a number of alternatives should be executed. As long as this decision requires a human decision maker, the operation can be connected with a passive resource.

3. Decision operation based on a local rule.

In this class of modelling it is necessary for a human decision maker to complete the decision operation based on his own, individual rule. This operation may have a temporal requirement for the decision maker as an active resource.

4. Decision operation based on cooperation relationships.

In this case a decision based on a global rule is made in which the cooperation relationships between several alternative decision makers are considered. Following the pattern of agent-based systems, task suppliers offer themselves for the execution of the tasks to one or more demanding agents to different conditions. The decision is thus related to which task suppliers will be engaged as a resource for the execution. The decision-making and selection processes may be completed without a temporal requirement.

As already mentioned above, the latter decision class is of little relevance for the manufacturing area due to its unrealistic nature and will not be considered further. The first three decision classes will be elucidated in the following using simulation approaches and application examples.

\section{MODELLING PASSIVE DESCISION MAKERS}

\subsection{Modelling Decisions in an Activity Network}

The most simple model of human decisions considers merely the decision operation without it influencing the logical sequence of succeeding work operations. This situation arises, for example, when dealing with routine tasks which have to be assigned to a decision maker as a passive resource. If this decision maker is also responsible for other work operations this could lead to a bottleneck in the manufacturing sequence. A typical example of this is the inspection of manufacturing processes, materials and finished products, but routine organizational decisions can also be modelled in this manner (for an example, Zülch, Rinn, and Strate 2001).

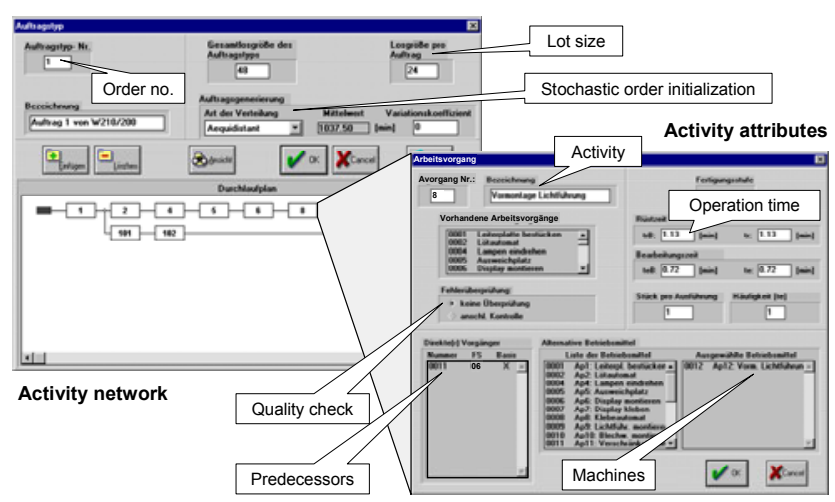

Figure 2: Modelling Assembly Operations with ESPE-QS (Zülch and Krüger 1999a, pp. 23)

In the following examples, various simulations procedures developed at the ifab-Institute of Human and Industrial Engineering of the University of Karlsruhe, in which manufacturing operations will be modelled as activity networks, will be used. Figure 2 shows an example of such a network in the simulation procedure ESPE-QS (German abbreviation for "Bottleneck-oriented simulation of personnel structures for quality assurance"). An activity network must be modelled for each order type. These activity networks can then be initialized as a manufacturing order repeatedly during the simulation run. Each activity in the network represents a work operation in the order requiring at least one assigned machine (or workplace) as well as at least one suitable person. Since automated work operations may also be modelled with this procedure, the standard times for the machine and personnel resources may differ.

\subsection{Case Example of a Partially Automated Assembly Line}

The application of this modelling approach can be shown on an example from the automotive components supplier 
industry (Zülch and Krüger 1999a; Zülch, Bongwald, and Krüger 1998). The assembly system being considered is a pulsed assembly line comprised of 7 automatic and 15 manual work stations. 12 employees work in the assembly system, all of which are capable of executing all occurring tasks. 4 variants of a product are manufactured, each in 18 to 20 work operations.

In the initial situation, the inspection of the finished products was carried out at the end of the assembly line at two automated and two manual inspection stations. The planning task was targeted at improving this type of inspection. This required that the various types of errors, their occurrence probabilities as well as possible consequences of the errors, such as rejects, rework and temporal prolongation of work operations, be determined and attributed to the originating work operations or work stations.

When considering the possible errors, the simulation showed that merely $86 \%$ of the statically planned output quantity could be attained. Even without this feedback of error consequences, the dynamic capacity of the assembly line reached only $91 \%$. This alone reflects the benefits of a simulation supported planning in contrast to a static calculation.

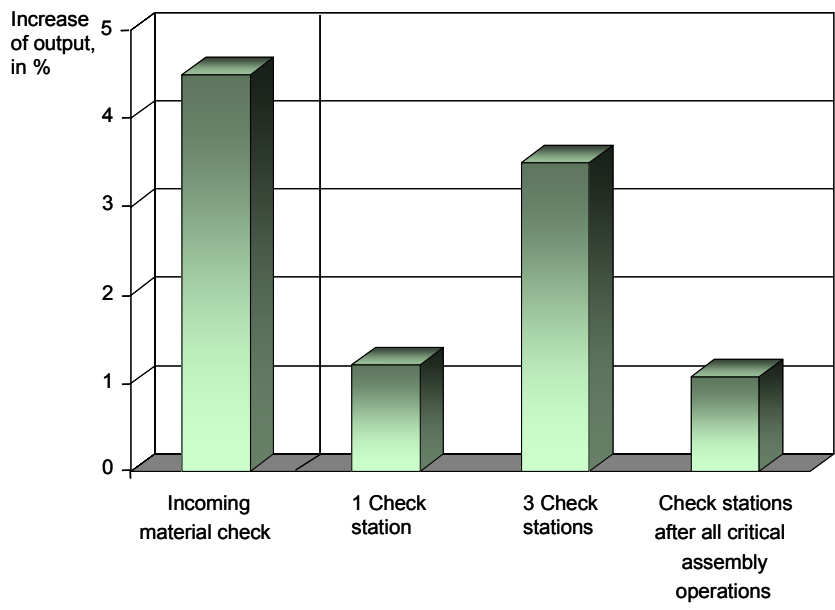

Figure 3: Simulation Results for Different Material and Process Checks

In a further simulation series, additional inspection operations were integrated into the assembly line. The modelling of an improved check of the incoming material resulted in a $4.5 \%$ increase of the output quantity in comparison with the initial situation (Fig. 3). Finally, further intermediate inspection stations were integrated into the simulation model, namely at those work stations with the highest error probabilities. The increased number of inspection stations led to shorter quality control loops, but also to longer throughput times. The highest output of $89.5 \%$ was attained in the simulation with three additionally integrated inspection stations. The implementation of further inspection operations led to a reduction of the output as a result of additional inspection times.

\section{MODELLING DECISION OPERATIONS WITH GLOBAL RULES}

\subsection{Decision Rules and Decision Situations}

During the simulation of decision operations with passive decision makers, merely the assignment of resources and the duration of the decision operations are indicated, while the result of the decision is shown either not at all or only as a given probability for alternative, succeeding operations (e.g., as empiric frequency of rejects). In contrast, in rule-based decision operations the decision is made based on a given rule whose influencing parameters result from the actual decision situation in the simulated manufacturing system. In the simulation run, the decision situation and its characterizing parameter values are subject to continual changes.

In order to illustrate the decision situation, an information system is required in which the values of the appropriate influencing parameters are provided at every point in time during the simulation run. Furthermore, a goal system is needed with which a choice from amongst alternative succeeding operations or states can be made based on a given decision rule. This goal system is modelled as one or more decision rules. Additionally, such a decision operation can be assigned to a decision maker, whereby the decision can only be made when this (or an alternative) person is available during the simulation run; furthermore, this then has a temporal requirement (Figure 4; Fischer 2004, pp. 86).

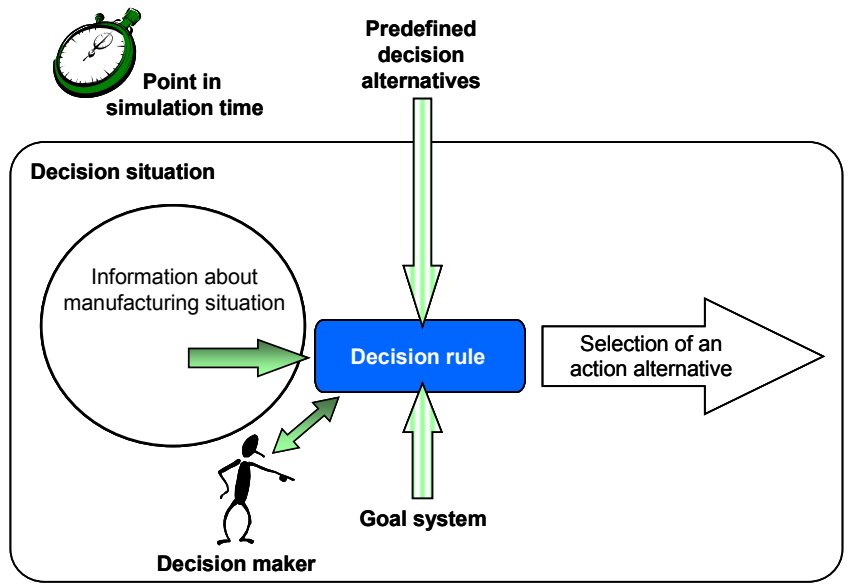

Figure 4: Modelling the Decision Situation

The most important decisions in the manufacturing area deal with the assignment of available personnel and machinery resources to work operations. Furthermore, when sequence alternatives are available, decisions as to 
which of these alternatives should be selected given the current manufacturing situation must be considered.

Figure 5 shows the user interface of the simulation procedure OSim, which stands for "Object simulator" (Jonsson 2000; Zülch, Fischer, and Jonsson 2000). The temporal-logical sequence of work operations is in turn modelled as an activity network, which, in addition to the standard and-relationships, also contains or-relationships of activities. Thus, a decision about an alternative path within the activity network must be made. In the case at hand, there are three possible alternative work operation sequences, whereby one path also contains an additional decision regarding the lot size of the work operation.

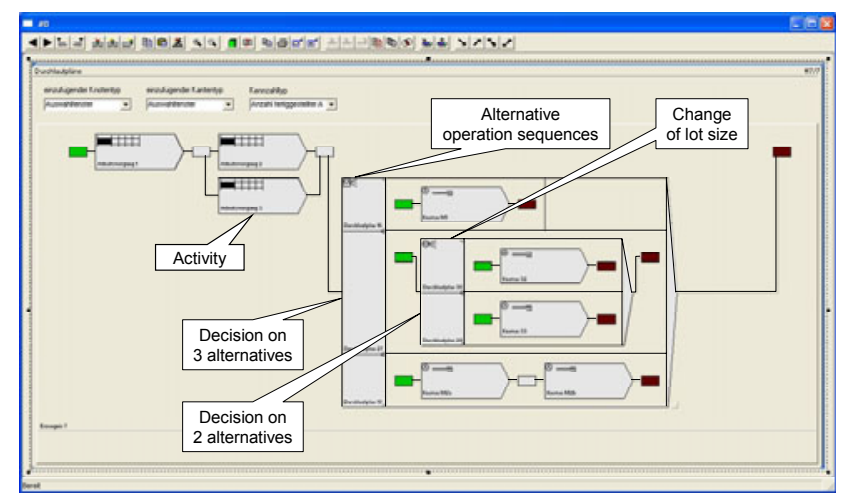

Figure 5: Modelling Activity Networks with Decision Notes in OSim (Zülch and Stock 2005, pp.13)

\subsection{Case Example for Personnel Assignment in a Repair Work System}

The presented method for modelling human decisions will be elucidated in the following using a case example of an industrial repair work system (Fischer 2004, pp. 217). The work system's function was comprised of repairing electric tools with the goal of completing all repair orders and having them ready for dispatch on the same day as they are registered in the order processing system. The work system was divided into work teams according to the type of electrical tool to be repaired. The goal system foresaw an ideal service rate of $100 \%$ of completed orders for one day, while also keeping the worker idle times as low as possible. The achievement of these goals was hindered in particular by the fact that repair orders were delivered by truck, leading to load peaks.

The simulation study was conceived to help clear up the question as to how a change to the working times of the existing work teams and their individual workers would affect the mentioned indices. For this purpose, first the shift starting and ending times were varied (Fig. 6). The shift end was varied in such a way that each individual worker could stop working earlier than the regular daily shift end if the expected capacity requirements for the afternoon were much lower than predicted. The result of the simulation study showed that a later shift begin would positively affect the examined indices. However, this solution was rejected by the workers.

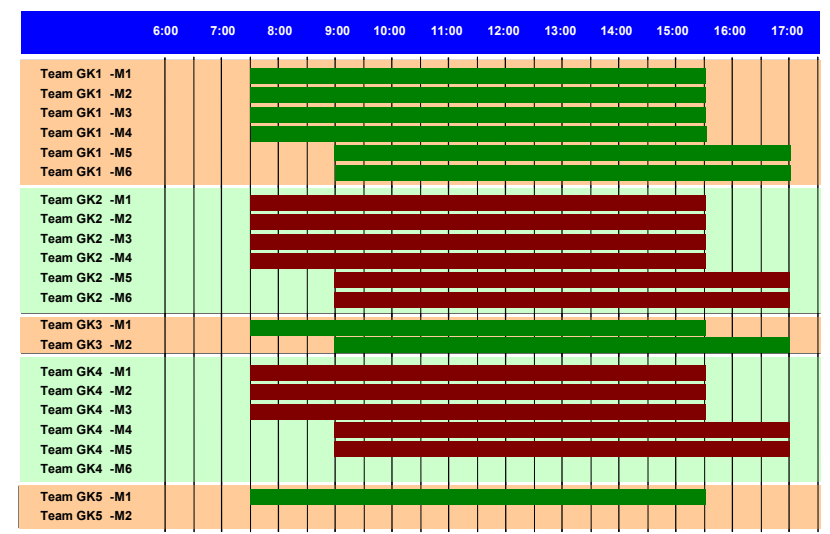

Figure 6: Model Variant for the Tour Plan of Repair Workers (Fischer 2004, pp. 275)

Therefore, a different solution had to be sought in order to align the personnel capacity supply with the daily capacity requirements. For this purpose, a further simulation study examining the effects of an improvement of the prognosis of the expected afternoon capacity requirements was carried out. In order to reproduce this in the simulation model, not only the occurring repair orders and their throughput were simulated, rather also the prognosis creation, on whose basis the workers were able to end their daily work earlier than regular.

For this prognosis not only did the waiting repair orders for each work system have to be recorded, but the quality of the prognosis also had to be varied. Three points in time during the day were chosen at which the capacity requirements should be predicted. The resulting decision regarding further personnel assignment was then compared with the decision made based on an ideal prognosis value. This ideal prognosis value was known in the simulation model for each simulated day.

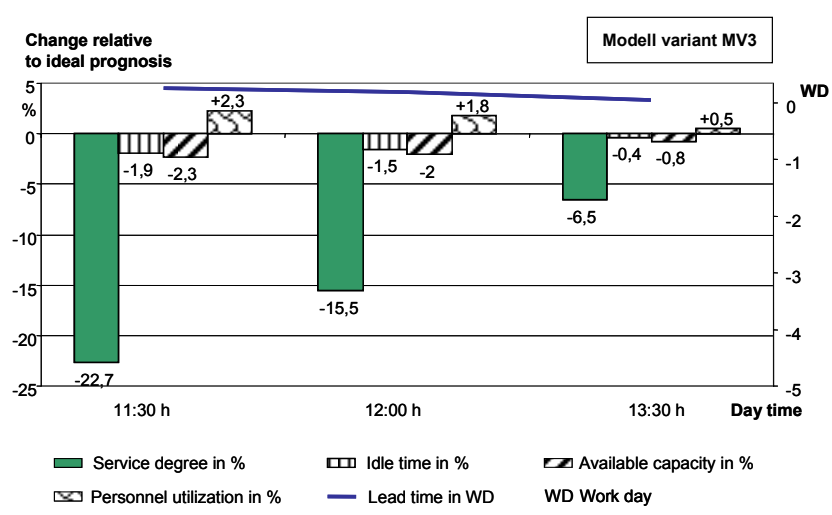

Figure 7: Production Logistical Key Figures Related to the Quality of Expected Work Load Prognosis 
The simulation results showed a clear effect of the prognosis quality on the production logistical key figures. However, it is natural that, even with a very good prognosis (in Fig. 7 at the latest point in time), a drop in the service rate was seen. Thus, the short-term alignment of the personnel supply was connected with the risk that waiting repair orders might not be completed on the same day. However, this had to be weighed against costs savings gained through capacity-oriented personnel control (see Zülch and Fischer 2004 for other aspects of this simulation project).

\section{MODELLING ACTIVE DECISION MAKERS}

\subsection{Consideration of Individual Action Preferences}

When modelling passive decision makers, the decision operations are simulated based on rules which are generally valid for the manufacturing system being simulated. Also, the values of influencing parameters are globally valid. The modelling of active decision makers assumes that their decisions are based on their own rules or at least on individual values of the influencing parameters. The decision is, therefore, not only dependent upon the decision situation, rather also upon the decision maker. The applied rule or even only their decision parameters are only locally valid so that the decision maker can also incorporate individual action preferences.

This approach was implemented in the simulation procedure ISIS (German abbreviation for "Interactive simulation of intelligent acting personnel structures") in such a way that an intelligently acting worker was modelled for the selection of action alternatives (Krüger 1999; Zülch and Krüger 1999a). The field of application is made up of partially automated manufacturing systems in which workers should be responsible for, in addition to order-related functions, the elimination of disturbances and preventive actions, such as the timely replenishment of material buffers.

In the model it was assumed that not only the decision situation and the goal system, rather also the consequences of the respective action alternatives influence the decision selection of a worker (Fig. 8; Krüger 1999, pp. 30). Since these correlations were basically unknown, action preferences dependent upon the respective decision situations were determined in the simulation procedure ISIS through interactive simulation. During the simulation, a test person took on the function of one of the workers represented in the model in real time. In an animation the manufacturing system was visualized as a functional layout and waiting work requirements were portrayed by the changed colour of the relevant machinery resource. Among other things, the transit times required to reach the action location, the local incompleteness of information from the concealment of resources as well as the stress to the test person as a result of other waiting tasks were thereby also simulated.

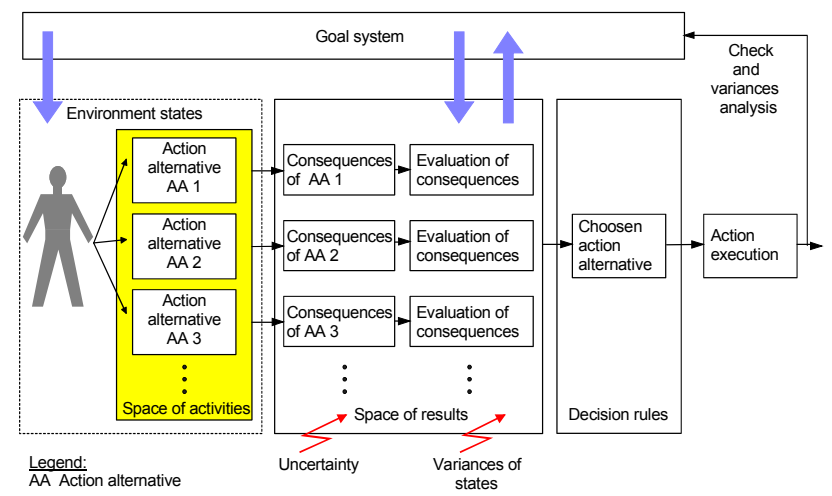

Figure 8: Model of Active Decision Making with Operation Alternatives

The goal of the examination was to analyze to what degree various goals (maximization of personnel utilization, minimization of equipment idle time) lead to the development of certain action preferences. The order type (preventative tasks, order functions or disturbance elimination), the proximity to the action location, the previous waiting time of existing work requirements, the availability of information as well as the presentation of performance figures were drawn upon as independent variables.

These variables were examined in a three-level factorial test design with two measurement repetitions on a total of 12 test persons with respect to their effects on the action preferences. Using a conjoint analysis (see, e.g., Gustafsson et al. 2003; Härdle and Simar 2003, pp. 393) the benefits of each individual attribute specification for the attainment of the specified goals (e.g., minimization of equipment idle time from occurring disturbances) are determined. Figure 9 shows the resulting dependence of action preferences to the type of feedback information, in this case the personal workload in comparison with the machine downtime as a result of disturbances (Zülch and Krüger 1999b, pp. 43).

\subsection{Comparison of Passive, Interactive and Active Action Models}

The action preferences determined in this manner were then integrated into the simulation procedure ISIS. In doing this, the individual test person was replaced by an automated decision routine based on the action preferences of the same test person. In a simulation study, the differences between the hitherto common reactive action model with passive resources and the interactive model with a reference test person and automated decision-making in an active action model were examined in this manner. While the latter two models were analyzed using the procedure ISIS, the modelling of the reactive action model was carried out 
using the simulation procedure ESPE (cf. chapter 1.2). The average personnel utilization achieved during the simulation of a predefined manufacturing programme was used as an evaluation criterion.

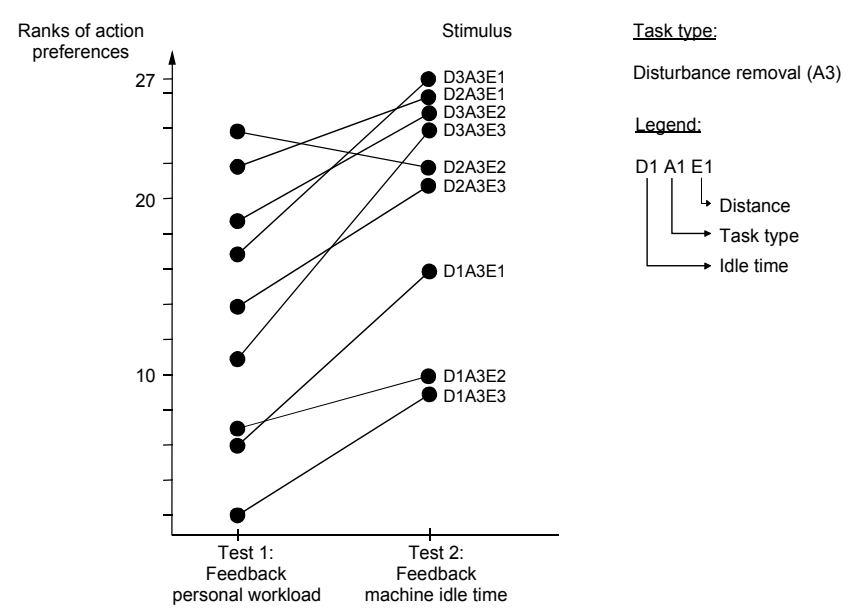

Figure 9: Ranks of Activity Preferences Dependent upon Feedback Information

Using the simulation procedure based on the reactive action model, the same value for personnel utilization is attained in each repetition of the test sequence, if the manufacturing and disturbance sequences occur deterministically. In contrast, the interactive model and the active action model with automated decision-making both showed a clear dispersion of the results attained by the 12 test persons with personal or automated decision-making (see the boxplot diagram in Fig. 10; cf. Krüger 1999, p. 126). The three listed test runs differed in the type of key figures that were fed back to the test persons as well as in the availability of information in the manufacturing system regarding the occurring disturbances.

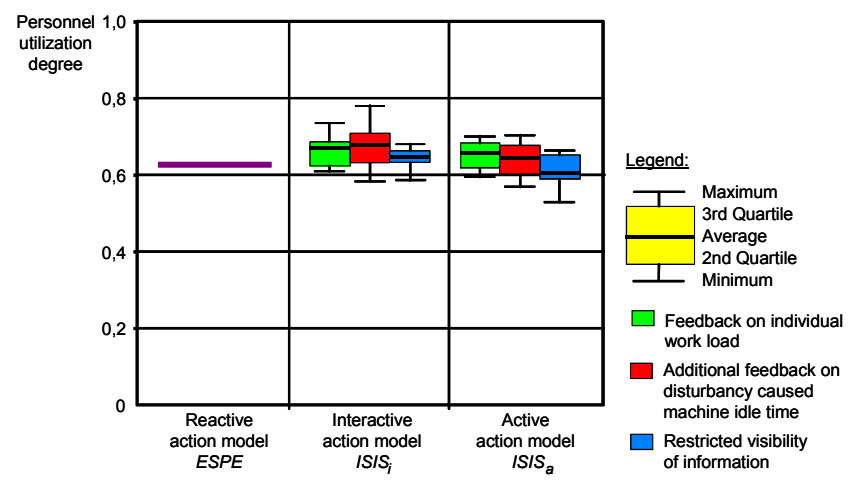

Figure 10: Comparison of Reactive, Interactive and Active Modelling of a Semi-Automatic Assembly System
The stability of decision-making gained as a result of the automatic determination of action preferences through conjoint analysis in the active action model led to a smaller dispersion of the significant key figure, namely personnel utilization. Furthermore, in contrast to the interactive test arrangement for automated decision-making, the case in which information was not readily available led to a noticeable $4 \%$ deterioration of the key figure. This effect can be traced back to the fact that the limited availability of information reinforced the proximity target dominance of the test person. This means that the test persons tended to choose a closer location for their next action than was the case in the automated sequence. This in turn led to an increase in the own personal utilization in the interactive test design.

\section{NECESSITY FOR FURTHER RESEARCH WORK}

The examples provided highlight that the modelling of human decisions with passive resources is merely a first step towards realistic simulation of decision making in the manufacturing area. As shown by the comparison of passive, interactive and active action models (chap. 4.2), the passive action model is not capable of revealing the possible variability and thus the uncertainty regarding assessment criteria. On the other hand, an interactive action model leads to simulation results which cannot be reproduced. As a result, active action models are preferred, even if they do not fully consider the variability of assessment criteria and possibly even contain technical modelling biases.

The existing insights into the representation of human decision-making in manufacturing processes require further expansion. As a supplement to a purely reactive model, the decision situation must be examined in more detail with respect to its effects on the decision selection. As a result it may be stated that detailed modelling of human decision-making contributes significantly to a more realistic simulation of decision-making processes in the manufacturing area.

Further research work will be targeted toward taking the quality of decision processes, with respect to their later effects, into account when modelling. On the one hand, this encompasses the effectiveness of decision processes, meaning the selection of a suitable action alternative with respect to the given goal system. On the other hand, this also has to do with the efficiency of decision processes, in other words their costs and duration as well as the costs and duration of the selected action alternative. Finally, a further field for research can be seen - as shown in the last application example - in the modelling of incomplete information and the simulation of its consequences. 


\section{ACKNOWLEDGMENTS}

The author thanks the German Research Association (Deutsche Forschungsgemeinschaft) for its support in the research work referred to in this paper. These endeavours are currently sponsored within a project dealing with the development of a simulation-based method for the analysis of decision systems in the production area ("Entwicklung einer simulationsbasierten Methode zur Analyse von Entscheidungssystemen im Produktionsbereich").

\section{REFERENCES}

Fischer, J. W. 2004. Ein generisches Objektmodell zur Modellierung und Simulation operativer Entscheidungen in Produktionssystemen. Aachen: Shaker Verlag. (ifab-Forschungsberichte, vol. 34)

Gustafsson, A., A. Herrmann, and F. Huber (Edts.). 2003. Conjoint Measurement. Berlin et al.: Springer, 3rd ed.

Härdle, W. and L. Simar. 2003. Applied Multivariate Statistical Analysis. Berlin et al.: Springer.

Häußermann, S. 1980. Mehrmaschinenbedienung führt zur Arbeitsbereicherung. In VDI-Nachrichten, Düsseldorf, 7, 15.02.1980, p. 24.

Jonsson, U. 2000. Ein integriertes Objektmodell zur durchlaufplanorientierten Simulation von Produktionssystemen. Aachen: Shaker Verlag. (ifab-Forschungsberichte, vol. 21)

Klauke, A. 1980. Entwicklung und Erprobung eines Simulationsmodells zur Planung der Arbeitsteilung an Arbeitssystemen mit numerisch-gesteuerten Werkzeugmaschinen. Diss., Univ. of Techn. Aachen.

Krüger, J. 1999. Entscheidungstheorie-basierte Simulation der Handlungsorganisation im Fertigungsbereich. Aachen: Shaker Verlag. (ifab-Forschungsberichte, vol. 20)

VDI 3633, part 6. 2001. Simulation von Logistik-, Materialfluss- und Produktionssystemen - Abbildung des Personals in Simulationsmodellen. Berlin: Beuth.

Zülch, G. 2000. Simulation der Aufbauorganisation in Produktionsunternehmen - Stand und Entwicklungspotenziale. In Betriebs- und Arbeitsorganisation im Wandel der Zeit. Edts.: H. Luczak, W. Eversheim, and V. Stich. Köln: TÜV-Verlag, pp. 123-140.

Zülch, G., O. Bongwald, and J. Krüger. 1998. Personalorientierte Simulation als Bindeglied zwischen Zeitwirtschaft und Fertigungssteuerung. In: FB/IE Fortschrittliche Unternehmensentwicklung und Industrial Engineering, Darmstadt, 47, 2, pp. 79-84.

Zülch, G. and J. Fischer, 2004. Increasing the Flexibility of Working Times and Personnel Control in an Industrial Repair Work System. <www.sim-serv.com/ white_papers.php > [accessed August 13, 2004].

Zülch, G., J. Fischer, and U. Jonsson, 2000. An integrated object model for activity network based simulation. In:
Proceedings of the 2000 Winter Simulation Conference. J. A. Joines, R. R. Barton, K. Kang, and P. A. Fishwick, eds.. Piscataway, NJ: The Institute of Electrical and Electronics Engineers et al., vol. 1, pp. 371380 .

Zülch, G. and J. Krüger, 1999a. Personalintegrierte und personalorientierte Simulation. In: Personalorientierte Simulation - Praxis und Entwicklungspotential. Edts.: Heel, J., and Krüger, J. Aachen: Shaker, pp. 9-28. (ifab-Forschungsberichte, vol. 19)

Zülch, G. and J. Krüger, 1999b. Ermittlung der Handlungspräferenzen von Fertigungsmitarbeitern bei der Planung von Bearbeitungsreihenfolgen mittels Conjoint-Analyse. In: Zeitschrift für Arbeits- und Organisationspsychologie, Göttingen, 43(NF 17), 1, pp. 36-45.

Zülch, G., A. Rinn, and O. Strate. 2001. Dynamic analysis of changes in decisional structures of production systems. In: International Journal of Production Economics, Amsterdam, 69, 2, pp. 239-252.

Zülch, G. and P. Stock. 2005. Self-organizing manufacturing control based on the ant colony approach. In: Modeling and Implementing the Integrated Enterprise. IFIP WG 5.7 Proceedings of the International Conference on Advances in Production Management Systems. 18.-21.09.2005, Rockville MD, 20 p. (CD$\mathrm{ROM})$

\section{AUTHOR BIOGRAPHY}

GERT ZÜLCH, Prof. Dr.-Ing. Dipl.-Wirtsch.-Ing., studied Mechanical Engineering at the Technical University of Braunschweig as well as Industrial Engineering at the Technical University of Aachen (Germany). Upon concluding his activity at an industry-oriented research institute, he was occupied in the Central Department for Manufacturing Economics and Organization at the Siemens headquarters in Munich. Since 1985 he is head of the ifabInstitute of Human and Industrial Engineering at the University of Karlsruhe, which he founded. He is a member of a number of international organizations, both in the fields of production management and ergonomics. Furthermore, he has on many occasions acted as a scientific expert, both nationally and abroad (European Commission, President of the French Republic, Academy of Finland, German Science Council, German Research Association, NorthrhineWestfalian Academy of Sciences etc.). His scientific interests range from communication ergonomics to the simulation of production systems with special attention to personnel assignment problems. 